\title{
O processo de planejamento e periodização do treino em futebol nos clubes da principal liga portuguesa profissional de futebol na época 2004/ 2005
}

CDD. 20.ed. 796.073

796.33

\author{
Pedro SANTOS* \\ J orge CASTELO** \\ Pedro Miguel SILVA**
}

*Faculdad de Ciencias de la Educación y del Deporte, Universidade de Vigo - Espanha. **Universidade Lusófono de Humanidades $e$ Tecnologias - Portugal. ***Faculdade de Desporto, Universidade do Porto - Portugal.

0 planejamento e a periodização são fases cruciais diretamente implicadas na eficácia, consistência e qualidade do jogo das equipes. Foram objetivos deste estudo investigar: 1) a implementação da dinâmica da "carga" e sua relação com os períodos; 2) a importância atribuida às componentes da "carga" e recuperação; 3) a prescrição da intensidade; 4) as componentes do rendimento consideradas no planejamento, sua importância hierárquica e, forma de trabalho; 5) o aspecto considerado central no planejamento; 6) o tipo de planejamento utilizado na preparação da equipe; e 7) a utilização da modelação no processo de treino. 0 universo estudado foi constituido pelas 18 equipes do principal escalão de Futebol, na época 2004/2005. Foi aplicado um inquérito por questionário validado por sete especialistas. Representando cada um dos clubes em estudo, responderam ao questionário 16 treinadores principais e dois adjuntos, por remessa do respetivo treinador principal. Os resultados sugerem que embora pareça não ser a corrente de treino dominante, o paradigma da dimensão física do treino aparece ainda bastante vincado. Alguns dos pressupostos associados à conceção tradicional do treino permanecem presentes. Parece ser costume operacionalizar um planejamento com base na dimensão tática. Apesar desta ser a "guia" do processo, e "arrastar" a dimensão física, nem sempre tal acontece. Embora surjam situações em que ainda se promove a separação das dimensões do rendimento, a referência passa por trabalhá-las, sempre que possivel, simultaneamente. A modelação do jogo é uma tendência na maioria dos clubes. Nem todos os treinadores agem de acordo com as suas convicções expressas.

UnIteRMos: Futebol; Treino; Planejamento; Periodização.

\section{Introdução}

O Futebol, institucionalizado em 1863 pela Football Association, é uma das modalidades desportivas mais populares do mundo. Embora se considere que a natureza do jogo se mantém inalterada, atualmente o Futebol tem-se vindo a estruturar num domínio altamente profissional. Como nos refere TANI (2001), a preparação para o desporto de rendimento é cada vez mais exigente. Tem-se entendido que não sendo o Futebol uma ciência, muito poderá beneficiar dos seus contributos (GARGANTA, 2001a), nomeadamente ao nível dos processos de organização do treino e do jogo.

O treino constitui a forma mais importante e mais influente de preparação dos jogadores para a competição (GARGANTA, 2004). Visa induzir alteraçóes positivas observáveis na performance dos jogadores e das equipes (GARGANTA, 2008).

Considerando-se que a prática e a instrução são os ingredientes chave na busca do sucesso (WILLIAMs \& Hodges, 2005), a investigação tem procurado debruçar-se sobre quais as metodologias mais eficazes para aprimorar o rendimento desportivo (BRAZ, 2006), sabendo-se "à priori” que são diversos e interatuantes os aspectos que concorrem para o rendimento desportivo em Futebol (BAUER \& UeberLe, 1988; Castelo, 2002; Garganta, 1991, 1997, 2002; MARQues, 1990) e que a expressão máxima das capacidades do jogador requer condições ótimas 
de preparação e de realização (QUINTA, 2004). Tal desígnio transporta o problema da complexidade.

A organização do treino em Futebol é um processo metodológico e pedagógico complexo, que visa a obtenção de elevados desempenhos competitivos pelas equipes e jogadores. SILVA (1998) considera o planejamento do treino a fase fulcral de toda a organização do processo de treino. Neste sentido, a problemática do planejamento e periodização do processo de treino é uma preocupação central de qualquer treinador, tendo este que equacionar uma diversidade de problemas de natureza metodológica.

$\mathrm{Na}$ busca de uma maior eficiência do processo de treino, os procedimentos, técnicas, sistemas e métodos empregues variaram bastante nas últimas décadas (Romero Cerezo, 2000). Existem várias formas de jogar e de conseguir resultados, do mesmo modo que existem várias maneiras de treinar (GARGANTA, 2004). Encontramos na literatura a emergência de várias correntes de treino aplicadas ao Futebol, que traduzem a própria evolução da história da Teoria e Metodologia do Treino Desportivo.

Fundamentalmente emergem duas tendências opostas ao nível do planejamento do treino em Futebol: uma que coloca o primado nos aspectos da "carga" e no planejamento da componente de rendimento "física" e outra, em linha oposta, que coloca o postulado no planejamento dos aspectos "táticos", centrando-se estes numa determinada forma de jogar. Considera-se que a dimensão física surge agregada à dimensão tática, entendida como "guia" do processo.

O realce atribuído aos aspectos físicos equaciona o paradigma da dimensão fisica ${ }^{1}$ do treino, em Futebol. Este fato advém da grande influência exercida pela fisiologia do exercício (TANI, 2001). No entanto, numa outra perspectiva, considera-se que o ensino/ treino deve ser edificado a partir de perspectivas e matrizes organizacionais, embora sem descorar as demais facetas do jogo (GARGANTA, 1997). Tem sido cada ver mais aceite que a esfera diretora do planejamento e periodização do treino em Futebol deverá ser a "tática". Surge pois uma necessidade de indagar e refletir acerca da realidade com que nos deparamos no processo de treino em Futebol, confrontandoa com os pressupostos teóricos de referência, no sentido de perceber o estado evolutivo, e promover uma intervenção sustentada e coerente com vista a preparar as equipes para o sucesso competitivo.

Os objetivos deste estudo foram traçados no sentido de investigar: 1) a implementação da dinâmica da "carga" e sua relação com os períodos; 2) a importância atribuída às componentes da "carga" e recuperação; 3) a prescrição da intensidade; 4) as componentes do rendimento consideradas no planejamento, sua importância hierárquica e, forma como são trabalhadas; 5) o aspecto considerado central no planejamento; 6) o tipo de planejamento utilizado na preparação da equipe; e 7) a utilização da modelação na orientação dos processos de treino.

\section{Métodos}

O universo em estudo é constituído pelas 18 equipes da Superliga da época 2004/2005, sendo alvo de inquérito os treinadores principais do escalão sênior dos referidos clubes. A metodologia utilizada na coleta de dados prendeu-se com a aplicação de um inquérito por questionário. Este é composto por 54 questões agrupadas em 41 perguntas das quais duas são abertas. Todas as outras são fechadas.

Os procedimentos de validação do questionário elaborado dividiram-se em duas fases. Numa primeira fase, foi apresentado o questionário a um especialista em investigação por questionário (sociólogo). Com base nas críticas e sugestôes apresentadas, ajustamos as questôes de modo a torná-las mais claras e objetivas. Estes ajustes consistiram, essencialmente, em alteraçôes ao nível da estrutura sintática das questões, assim como ao nível da estrutura gráfica de apresentação. Numa segunda fase, dividimos os procedimentos de validação em três etapas. Foi utilizada uma amostra composta por seis especialistas da área das Ciências do Desporto. Em cada uma das etapas, o questionário foi apresentado a dois elementos que apresentaram críticas e sugestões. No final de cada etapa o questionário foi reformulado com base nas críticas consideradas relevantes.

$\mathrm{Na}$ coleta dos dados, foram contatados os treinadores principais de cada um dos 18 clubes da Superliga da época 2004/2005. Em representação cada um dos clubes em estudo, responderam ao questionário 16 treinadores principais e dois adjuntos, após indicação do treinador principal. Foi explicado aos inquiridos o âmbito do trabalho, realçando o anonimato e confidencialidade e solicitado consentimento para utilização dos dados. O estudo foi validado pelo 
Conselho Ético do Conselho Científico Faculdade de Motricidade Humana, respeitando as "Diretrizes Éticas Internacionais para a Pesquisa Envolvendo Seres Humanos" (CIOMS e OMS²).

A coleta de dados realizou-se entre os dias 10 de fevereiro de 2005 e 10 de maio de 2005. O preenchimento do questionário foi presencial em

\section{Resultados}

Apresentamos os principais resultados das equipes da Superliga no que se refere a aspectos do processo de planejamento (TABELA 1).

$\mathrm{Na}$ Superliga é costume atender-se às fases da forma desportiva, assentes na dinâmica da "carga" (56\%), assim como à divisão da época em Períodos, com diferenças de manipulação no volume e na intensidade (61\%) (concepção tradicional). Tal não se verifica nos restantes clubes.

Nos clubes que referem dividir a época em Períodos, com diferenças no volume e na intensidade, identifica-se um padrão geral: mais volume e menos intensidade no Período Preparatório, menos volume e mais intensidade no Período Competitivo (lógica inversa) e menos volume e menos intensidade no Período de Transição.

Constata-se que é usual nestes clubes orientar o treino à intensidade máxima (83\%), no qual,
11 casos $(61,11 \%$ dos clubes inquiridos) e não presencial em sete $(38,89 \%$ dos clubes inquiridos). Somente em duas destas situaçôes $(11,11 \%$ dos clubes) a entrega ao inquirido não foi presencial.

Os dados foram trabalhados na base de dados "Excel", recorrendo-se à percentagem com arredondamento a duas casas decimais.

o volume de treino está subjugado às intensidades máximas aplicadas (78\%).

Todos os treinadores referem a intenção de orientar o processo de planejamento para os designados "patamar de rendimento".

Embora às componentes da "carga" (volume, intensidade e intensidade máxima relativa) seja atribuída importância, são consideradas de "muito importante" a intensidade (83\%) e a intensidade máxima relativa $(72 \%)$.

A recuperação é considerada uma problemática do treino "muito importante", sendo atribuído o maior destaque aos aspectos da fadiga "fisiológica" (94\%), seguindo-se os da fadiga "central" (78\%).

$\mathrm{Na}$ TABELA 2 analisamos as componentes do rendimento consideradas bem como aspetos da sua operacionalização. 
TABELA 1 - Percentagem de clubes em função (A) da utilização das fases da forma desportiva e da divisão da época em períodos, (B e C) da gestão da intensidade no treino, (D) da existência de patamares ou picos de forma, e (E) da importância atribuída às componentes da "carga".

* "B" reporta-se ao subgrupo de 11 treinadores que referem utilizar estes aspetos no planejamento.

\begin{tabular}{|c|c|c|c|c|c|}
\hline \multirow{4}{*}{ A } & \multirow{2}{*}{ Variáveis do planejamento efetuado no clube: } & \multicolumn{4}{|c|}{ Total \% } \\
\hline & & \multicolumn{2}{|l|}{ Sim } & \multicolumn{2}{|c|}{ Não } \\
\hline & $\begin{array}{l}\text { - Atendem às fases da forma desportiva (aquisição, manutençãao } \\
\text { e perda da forma desportiva), assentes na dinâmica da "carga" }\end{array}$ & \multicolumn{2}{|c|}{55,56} & \multicolumn{2}{|c|}{44,44} \\
\hline & $\begin{array}{l}\text { - Atendem a divisão da época em períodos (preparatório, } \\
\text { competitivo e de transição), com diferenças de manipulação } \\
\text { no volume e na intensidade }\end{array}$ & \multicolumn{2}{|c|}{61,11} & \multicolumn{2}{|c|}{38,89} \\
\hline \multirow{6}{*}{$\mathrm{B}$} & \multirow{3}{*}{$\begin{array}{l}\text { Manipulações no volume e intensidade em função do Perío- } \\
\text { do da época (subgrupo de } 11 \text { clubes *): }\end{array}$} & \multicolumn{4}{|c|}{ Subgrupo } \\
\hline & & \multicolumn{2}{|c|}{ Volume } & \multicolumn{2}{|c|}{ Intensidade } \\
\hline & & Menos & Mais & Menos & Mais \\
\hline & - Período Preparatório & 0 & 100 & 81,82 & 18,18 \\
\hline & - Período Competitivo & 90,91 & 9,09 & 0 & 100 \\
\hline & - Período de Transição & 100 & 0 & 90,91 & 9,09 \\
\hline \multirow[t]{5}{*}{$\mathrm{C}$} & Intensidade do treino: & \multicolumn{2}{|l|}{ Sim } & \multicolumn{2}{|c|}{ Não } \\
\hline & \multirow[t]{2}{*}{$\begin{array}{l}\text { - No treino, a intensidade é quase sempre a máxima (exceção } \\
\text { dos aspectos de recuperação) }\end{array}$} & \multicolumn{2}{|c|}{83,33} & \multicolumn{2}{|c|}{16,67} \\
\hline & & Sim & Não & Sim & Não \\
\hline & $\begin{array}{l}\text { - O volume de treino está subjugado às intensidades } \\
\text { máximas aplicadas }\end{array}$ & 77,78 & 5,55 & & \\
\hline & $\begin{array}{l}\text { - A prescrição da «intensidade» está intimamente relacio- } \\
\text { nada com a prescrição do «volume» }\end{array}$ & & & $11,11 \%$ & $5,56 \%$ \\
\hline \multirow[t]{3}{*}{$\mathrm{D}$} & Orientação expressa para o processo de planejamento: & & & & \\
\hline & - Patamares de rendimento & \multicolumn{4}{|c|}{100} \\
\hline & - Picos de forma & \multicolumn{4}{|c|}{0} \\
\hline \multirow[t]{6}{*}{$\mathrm{E}$} & $\begin{array}{l}\text { Importância atribuída às componentes da "carga" } \\
\text { e recuperação: }\end{array}$ & $\begin{array}{l}\text { Pouco } \\
\text { importante }\end{array}$ & $\operatorname{Imp}$ & tante & $\begin{array}{l}\text { Muito } \\
\text { importante }\end{array}$ \\
\hline & - Volume & 5,56 & & & 33,33 \\
\hline & - Intensidade & 5,56 & & & 83,33 \\
\hline & - Intensidade máxima relativa & 0 & & & 72,22 \\
\hline & - Recuperação da fadiga "fisiológica" & 0 & & & 94,44 \\
\hline & - Recuperação da fadiga "central" & 0 & & & 77,78 \\
\hline
\end{tabular}


TABELA 2 - Percentagem de clubes em função (A) das componentes do rendimento utilizadas, (B) da forma como são trabalhadas, (C) do aspeto central e (D) principal tipo de planejamento, e (E) da forma de trabalho das capacidades "físicas".

\begin{tabular}{|c|c|c|}
\hline \multirow[t]{9}{*}{ A } & Componentes do rendimento: & Total \% \\
\hline & - "Física” & 100 \\
\hline & - "Técnica” & 100 \\
\hline & - “Tática” & 100 \\
\hline & - "Psicológica" & 94,44 \\
\hline & - “Outra”: & \\
\hline & - Volitiva & 16,67 \\
\hline & - Estratégica & 11,11 \\
\hline & - Sociológica & 5,56 \\
\hline \multirow[t]{3}{*}{ B } & Forma como as componentes do rendimento são trabalhadas: & \\
\hline & $\begin{array}{l}\text { - Simultaneamente, sempre que possível, através de exercícios "tático-técnicos” que implicam } \\
\text { também a componente física }\end{array}$ & 77,78 \\
\hline & $\begin{array}{l}\text { - Em separado e simultaneamente, através de exercícios analíticos (físicos e/ou técnicos) e "tático- } \\
\text { técnicos" que implicam também a componente física }\end{array}$ & 22,22 \\
\hline \multirow[t]{7}{*}{$\mathrm{C}$} & Aspecto central do planejamento no treino de Futebol: & \\
\hline & - A componente "tática" dos jogadores/equipe; & 5,56 \\
\hline & - A componente "tático-técnica" dos jogadores/equipa e, por "arrastamento" desta a componente física & 72,22 \\
\hline & $\begin{array}{l}\text { - A componente "física" dos jogadores/equipe e, por "arrastamento" desta, a componente "tático-técnica" } \\
\text { - "Outra": }\end{array}$ & 5,56 \\
\hline & $\begin{array}{l}\text { - A componente psicológica e a componente "tático-técnica" dos jogadores/equipe e, por } \\
\text { "arrastamento" desta, a componente física }\end{array}$ & 5,56 \\
\hline & - A componente "física" dos jogadores/equipe, embora todas elas sejam iguais em importância & 5,56 \\
\hline & - A componente "tático-técnica" dos jogadores/equipe e, por "arrastamento" desta, todas as outras & 5,56 \\
\hline \multirow[t]{3}{*}{$\mathrm{D}$} & Tipo de planejamento utilizado para preparar a equipe para o jogo: & \\
\hline & - Planejamento com base na componente "física" & 11,11 \\
\hline & - Planejamento com base na componente "tática" (relativo a uma forma de jogar): & 88,89 \\
\hline \multirow[t]{3}{*}{$\mathrm{E}$} & $\begin{array}{l}\text { Orientação das respostas no subgrupo "planejamento com base na componente «tática»" (subgru- } \\
\text { po de } 16 \text { clubes*): }\end{array}$ & \\
\hline & - O desenvolvimento das capacidades "físicas" é subordinado aos aspectos do planejamento tático & $77,78^{* *}$ \\
\hline & - O desenvolvimento das capacidades "físicas" é independente do planejamento da componente "tática" & $11,11^{* *}$ \\
\hline
\end{tabular}

* (B) reporta-se ao subgrupo dos 16 treinadores que referem realizar um planejamento com base na componente "tática".

** As percentagens apresentadas em (E) reportam-se às opções do subgrupo considerando no contexto de todos os inquiridos ( $\mathrm{n}$ $=18$ ). Ao consideramos isoladamente o subgrupo $(\mathrm{n}=16)$, obtemos respetivamente, uma percentagem de 87,50 e $12,50 \%$.
No processo de planejamento são utilizadas as componentes "física", "técnica", "tática” e "psicológica" (dimensōes tradicionais). Podemos encontrar "outras", no entanto, as tradicionais são consideradas as críticas.

Sempre que possível, as componentes do rendimento são trabalhadas simultaneamente (78\%). Para tal, utilizam-se exercícios "tático-técnicos" que implicam também a componente física. Há clubes (22\%) que promovem também o trabalho em separado, utilizando além dos anteriores, também exercícios analíticos físicos e/ou técnicos.

A maioria dos treinadores (89\%) privilegia como aspecto central do planejamento o "tático-técnico", operacionalizando um planejamento com base na componente "tática", relativo a uma forma de jogar.

Apesar de haver quem refira que desenvolvimento das capacidades "físicas" da equipe e dos jogadores é independente do planejamento da componente "tática", na maioria dos clubes (78\%) o desenvolvimento das capacidades "físicas" está subordinado aos aspectos do planejamento tático.

$\mathrm{Na}$ Superliga, há treinadores que entendem que o aspecto central é a dimensão "física" (11\%), realizando um planejamento com base nesta dimensão.

A TABELA 3 reporta-se à importância atribuída pelos treinadores às componentes do rendimento. 
TABELA 3 - Percentagem de clubes em função da importância atribuída às componentes do rendimento.

* (B) reporta-se ao subgrupo dos 12 treinadores que atribuem a mesma importância às componentes do rendimento.

** (C) reporta-se ao subgrupo dos seis treinadores que atribuem importâncias distintas às componentes do rendimento

\begin{tabular}{|c|c|c|c|}
\hline & & \multicolumn{2}{|c|}{ Total \% } \\
\hline & & Sim & Não \\
\hline A & As componentes do rendimento têm todas a mesma importância & 66,67 & 33,33 \\
\hline \multirow[t]{7}{*}{ B } & $\begin{array}{l}\text { "Apesar de se considerar que todas as componentes do rendimento } \\
\text { têm igual importância, a "guia" do processo de planejamento do } \\
\text { treino é" (subgrupo de } 12 \text { clubes *): }\end{array}$ & \multicolumn{2}{|c|}{ Subgrupo "Sim" } \\
\hline & - A componente física & & 8,33 \\
\hline & - A componente tática & & 58,33 \\
\hline & \multicolumn{3}{|l|}{ - Outra: } \\
\hline & - A componente psicológica & & 16,67 \\
\hline & - A componente tática, a psicológica e sociológica & & 8,33 \\
\hline & - A componente tática e a estratégica & & 8,33 \\
\hline $\mathrm{C}$ & $\begin{array}{l}\text { "A componente mais importante para o processo de planejamento } \\
\left.\text { do treino é" (subgrupo de } 6 \text { clubes }{ }^{* *}\right) \text { : }\end{array}$ & \multicolumn{2}{|c|}{ Subgrupo "não" } \\
\hline & - A componente tática & & 33,33 \\
\hline & - A componente física & & 16,67 \\
\hline & - A componente psicológica & & 16,67 \\
\hline & - As componentes física e tática & & 16,67 \\
\hline & - As componentes tática e psicológica & & 16,67 \\
\hline
\end{tabular}

Há uma divergência relativa à importância hierárquica atribuída às dimensões do rendimento. $\mathrm{Na}$ maioria dos clubes (67\%) é-lhes atribuída a mesma importância.

Independentemente de se atribuir ou não igual importância às diversas dimensões do rendimento, a componente tática, quer "sozinha", quer em conjugação com outra(s) componente(s), é considerada como a "guia" do processo na maioria dos clubes.

Apresentamos na TABELA 4 a importância atribuída ao modelo de jogo e a sua utilização.

TABELA 4 - Percentagem de clubes (A) em função da importância atribuída ao modelo dejogo, e(B) sua utilização na orientação do processo de treino e de jogo.

\begin{tabular}{llcc}
\hline & & \multicolumn{2}{c}{ Total\% } \\
\cline { 3 - 4 } & & $\begin{array}{c}\text { Pouco } \\
\text { importante }\end{array}$ & Importante $\begin{array}{c}\text { Muito } \\
\text { importante }\end{array}$ \\
\hline A $\quad$ Importância atribuída ao modelo de jogo & 5,56 & 16,67 & 77,78 \\
\hline & & Sim & Não \\
\hline B $\quad \begin{array}{l}\text { Utilização do modelo de jogo como elemento orientador do } \\
\text { processo de treino e de jogo }\end{array}$ & 88,89 & 11,11 \\
\hline
\end{tabular}

Apesar de, na Superliga, existir quem relativize a importância do modelo de jogo adotado, este é, de forma quase unânime, considerado um elemento com importância. Na maioria dos clubes (78\%) é-lhe atribuída máxima importância. $\mathrm{O}$ modelo de jogo é utilizado como elemento orientador do processo de treino e de jogo em quase todas as equipes da Superliga (89\%).

$\mathrm{Na}$ TABELA 5 apresentamos alguns aspectos referentes à elaboração dos modelos de jogo. 
TABELA 5 - Percentagem de clubes que utilizam o modelo de jogo ( $\mathrm{n}=16$ ) em função (A) da abrangência contemplada pelo modelo, (B) da forma de estruturação, (C) dos momentos alvo, e (D) da sua adaptação aos jogadores.

\begin{tabular}{|c|c|c|}
\hline & & $\begin{array}{l}\text { Total } \% \\
\text { Subgrupo de } 16 \text { clubes* }\end{array}$ \\
\hline \multirow[t]{3}{*}{ A } & Abrangência do modelo de jogo: & \\
\hline & $\begin{array}{l}\text { Contempla o completamento desejado dos jogadores no plano coletivo (relativo } \\
\text { à articulação da equipe) }\end{array}$ & 100 \\
\hline & $\begin{array}{l}\text { Contempla o completamento desejado dos jogadores no plano individual (rela- } \\
\text { tivo à posição/função) }\end{array}$ & 100 \\
\hline \multirow[t]{4}{*}{ B } & Estruturação do modelo de jogo: & \\
\hline & $\begin{array}{l}\text { Estruturado, mas somente sob a forma de pensamento (sistematização mental } \\
\text { das ideias de jogo) }\end{array}$ & 37,50 \\
\hline & Estruturado num documento escrito & 62,50 \\
\hline & $\begin{array}{l}\text { Estruturado num documento escrito entregue ao Departamento de Formação } \\
\text { (para orientar a formação desportiva do clube num modelo de equipe e de } \\
\text { jogador a desenvolver) }\end{array}$ & 0 \\
\hline \multirow[t]{7}{*}{ C } & Momentos que o modelo de jogo apresenta: & \\
\hline & Organização ofensiva & 93,75 \\
\hline & Organização defensiva & 93,75 \\
\hline & Transição ataque/defesa (transição defensiva) & 93,75 \\
\hline & Transição defesa/ataque (transição ofensiva) & 100 \\
\hline & Lances de bola parada (fragmentos constantes do jogo) & 100 \\
\hline & Outro $^{3}$ & 37,50 \\
\hline \multirow[t]{3}{*}{$\mathrm{D}$} & Adaptação do modelo de jogo: & \\
\hline & $\begin{array}{l}\text { O modelo de jogo inicialmente delineado é adaptado às capacidades, caracterís- } \\
\text { ticas e entendimento dos jogadores }\end{array}$ & 87,50 \\
\hline & $\begin{array}{l}\text { O modelo de jogo inicialmente delineado não é adaptado às capacidades, carac- } \\
\text { terísticas e entendimento dos jogadores }\end{array}$ & 12,50 \\
\hline
\end{tabular}

$\mathrm{Na}$ maioria destas equipes verifica-se que o modelo de jogo:

- Contempla o comportamento desejado no plano coletivo (relativo à articulação da equipe) e, no plano individual (relativo à posição/função).

- Encontra-se estruturado num documento escrito, que nunca é entregue ao Departamento de Formação no sentido de orientar a formação do clube num modelo de equipe e de jogador a desenvolver.

- Apresenta os momentos: organização ofensiva, organização defensiva, transição ataque/defesa, transição defesa/ataque, fragmentos constantes do jogo e, outros ${ }^{4}$.

- Após a definição inicial, é adaptado às capacidades, características e entendimento dos jogadores.

\section{Discussão}

Em termos do planejamento efetuado (TABELA $1 \mathrm{~A}$ e $1 \mathrm{~B})$, podemos associar o posicionamento da maioria dos clubes à concepção tradicional. Apesar de colocada em questão, a dinâmica da "carga" ainda é considerada um pressuposto fundamental. A divergência é reveladora da existência de formas diversas
* A tabela reporta-se ao subgrupo dos 16 treinadores que referem utilizar o modelo de jogo como elemento orientador do processo de treino e de jogo. para a elaboração da periodização. Estas suportam-se em paradigmas distintos sobre o processo.

Uma investigação de Gomes (2004) junto de 35 treinadores de Futebol que atuam nas principais realidades competitivas em Portugal ${ }^{5}$, na época 2002/2003, confirma que o modelo de periodização 
mais utilizado apresenta variações na intensidade e volume ao longo da época desportiva.

No contexto da atual realidade desportiva tem-se questionado a aplicação da teoria clássica de periodização elaborada por Matvéiev e seguidores (GODOY, OLIVEIRA, Araújo, Sequeiros, Barbosa, Costa, Portal, Silva, Azevedo \& Dantas, 2004; Sequeiros, Castanhede, Oliveira \& Dantas, 2005; Silva, Martins \& Silva, 2004). Às objeções não será alheio as transformações no sistema de competições (BORIN, PrESTES \& MOURA, 2007; Sequeiros et al., 2005). Como nos refere GARGANTA (1993), a relação de quase confronto entre o volume e a intensidade, assim como, o compromisso estereotipado entre preparação geral e específica constituem-se como fatores perturbadores de uma periodização adequada no Futebol.

Embora através de programas de periodização se vise controlar e variar, numa base não-linear, as principais variáveis do treino (intensidade, volume e repouso), face aos objetivos de treino (BROwN \& GreENWOOD, 2005), fazendo evoluir a forma dos atletas, ao longo da época, através do que ABRANTES (1992) designa de interação entre o volume e a intensidade da carga (assim como uma passagem progressiva dos exercícios gerais para os específicos e especiais), no Futebol a periodização deve pois ser entendida numa perspectiva peculiar. Será de esperar um nível maximal de forma, com poucas flutuaçóes e maior estabilidade (GARGANTA, 1991). Grandes oscilações da carga, sejam elas ondulatórias ou pendulares, são inviabilizadas (GARGANTA, 1993). Em detrimento do princípio da progressão deve promoverse o da estabilização (SILVA, 1988, 1998), garantindo uma conservação do estado de forma. Neste contexto, deve-se estabilizar a forma a um nível um pouco abaixo do que seria um máximo absoluto (CARVALHAL, 2001), alcançando o "nível de alta forma" proposto por BOMPA (1984, citado por GARGANTA, 1993).

Temos de ser críticos ao enquadrar a importância dos períodos no seio do planejamento (ver TABELA 1A e 1B). A dinâmica da "carga" associa-se a um perfil demarcado, sintetizado por Silva (1998) como uma certa oposição entre as ondas de volume e de intensidade. Tal abordagem implica um caráter ondulatório da "carga" e, como tal, arrasta a noção da "curva da forma”, o que não parece muito oportuno no Futebol.

Seria de encontrar mais clubes a rejeitar o postulado referente à divisão da época em Períodos, com diferenças de manipulação no volume e intensidade. A ele associa-se uma visão tradicional do processo, tratando-se, conforme ArRUDA, Goulart, Oliveira, Puggina e Toledo (1999) de métodos desatualizados. Os modelos tradicionais não são coerentes com o extenso calendário competitivo do Futebol e a evolução do desporto moderno (PANTAlEÃo \& AlVARENGA, 2008). Embora se refiram principalmente para o caso do Brasil, as anotações de Arruda et al. (1999) e Silva, Martins e SiLva (2004) salientando ainda a grande utilização destes métodos, colaboram os resultados que obtivemos. Na mesma linha, uma investigação de SequeIros et al. (2005) constata que na literatura específica o modelo tradicional ainda é citado como o modelo que propicia uma performance mais adequada, aplicável e abrangente ao nível da estrutura da periodização e variação das cargas de treino. Um exemplo desta visão é-nos proposto por Alvarez del Villar $(1987)^{7}$, referindo que o ciclo de treino deverá comportar três períodos: 1) período preparatório sobre o qual se edifica a forma desportiva; 2) período de competiçóes, nos quais se criam dos pressupostos da forma desportiva e; 3 ) período de transição que significa recuperação ativa.

Tipicamente, o perfil identificado na TABELA 1B representa a concepção tradicional (ver SILVA, 1998). Contudo, tem vindo a ganhar preponderância uma outra perspectiva na qual: 1) não se utiliza a preparação geral como base para o restante da temporada (Pantaleão \& Alvarenga, 2008); 2) não deve ser dada muita importância à dinâmica da "carga" e ao volume de treino (ABRANTES, 1992), procurando-se antes conciliar o volume com a intensidade, mantendo-se esta com ligeiras oscilações, sempre a níveis muito elevados durante a época (Silva, 1998). Direciona-se o trabalho para a intensidade, no qual o volume é um volume de intensidades máximas acumuladas (CARVALHAL, 2001), i.e., o somatório de frações de máxima intensidade (volume da qualidade) (Mourinho, 2001).

A investigação tem demonstrado que sessões de treino intensas são essenciais para se manter o nível físico ótimo do jogador ao longo da época (ver BANGSBO, 1993), contudo os treinos que envolvem exercícios de alta intensidade são difíceis de controlar (Borin, Gomes \& Leite, 2007). Para o efeito, uma das principais preocupações da regulação dos programas de treino dos futebolistas relaciona-se com a regulação da intensidade de treino (SASSI, Reilly \& Impellizzeri, 2005). Considera-se que demasiados estímulos de intensidade máxima podem levar à exaustão e a um decréscimo no desempenho, tornando-se necessário que dias de treino com estímulos de alta intensidade alternem com dias de baixa intensidade, potenciando a recuperação (BOMPA, 
2002). A correta sequência das cargas deve estar fundamentada tanto na magnitude como na interrelação das diferentes capacidades físicas e sua recuperação (Borin, Gomes \& LeITe, 2007). BAngsbo, MoHr \& KrUstrup (2006) apresentam um exemplo para o programa semanal de treino, perseguindo objetivos distintos em cada dia, ajustada à situação competitiva com um ou dois jogos semanais.

Pelo exposto, deverão ser ministradas sessões intensas, ajustadas para o treino de diferentes objetivos, alternadas com sessões de recuperação, regulando a dinâmica semanal dos períodos de esforço/ recuperação. Como salientam Borin, GOMES e LeITE (2007), os jogos serão os balizadores da elaboração do microciclo de trabalho.

A necessidade de recorrer a alta intensidade surge desde o início da pré-temporada. De fato, BANGSBO (1993) concluiu que para desenvolver uma alta performance física para o início das competições, tornase necessário, durante a pré-época, realizarem-se jogos com regularidade, a nível competitivo elevado, devendo estes ser complementados por frequentes sessôes de treino de alta intensidade.

Neste enquadramento surge proposta de periodização de Mourinho (2001): no início da época, inicia-se o trabalho com intensidades altas relativas, que aumentam progressivamente até a um nível considerado ótimo, mantendo-o até final; no período das competições, os valores das intensidades devem manter-se sempre altos e, os valores dos volumes das intensidades vão subindo até a um momento ótimo, estabilizando posteriormente. Também CARVALHAL (2001) advoga o trabalho com intensidades altas. Sugere que, no início, o volume das intensidades deve ser baixo, pois considera-se que o organismo ainda não está adaptado; o volume das intensidades aumenta progressivamente, desde o primeiro dia de treino até a um nível considerado ótimo, mantendose aí até ao final.

O exposto evidencia que o volume está integrado na intensidade (que é sempre elevada), numa relação de simbiose. O inverso passa também a ser verdade, i.e., o treino específico requer volumes com intensidades máximas a intensidades ótimas acumuladas. Alertamos, porém, a necessidade de desenvolver investigação empírica para examinar experimentalmente o efeito destas propostas. Conforme MourINHO (2001), verifica-se uma relação constante entre o volume das intensidades, a densidade e a quantidade competitiva. O pressuposto do trabalho em intensidade elevada requer uma particular atenção à já de si importante problemática da recuperação ${ }^{8}$.
Paradoxalmentente, apesar das intenções postuladas para a dinâmica da carga, é usual na Superliga a orientação do treino para a intensidade máxima, excetuando quando são trabalhados aspectos da recuperação das equipes e jogadores (TABELA 1C). Face ao acima mencionado, este aspecto adequa-se ao treino no Futebol. De referir, a intenção de trabalhar, em todos os clubes, com "mais intensidade" no Período Competitivo, i.e., a grande parte da época (TABELA 1B). A exercitação deverá ser promovida através duma intensidade elevada. Esta orientação não vai de encontro com a concepção tradicional, onde se destaca a referida oposição no binômio volume/intensidade. Indícios de contradições parecem evidentes na resposta de alguns treinadores.

Entendendo que o volume pode ser caracterizado pela distância percorrida durante o jogo e pelo número de ações realizadas (PINTO, 1991), podemos considerar o volume como a soma das intensidades máximas relativas ${ }^{9}$ porquanto estas referem-se, à intensidade de desempenho adequada e necessária para se realizar uma dada ação de jogo, com eficácia. Os resultados indicam que na Superliga, o "volume de treinos está subjugado às intensidades máximas aplicadas" (TABELA 1C). Apenas um treinador não concorda com a afirmação. O treinador contradiz-se uma vez que refere no questionário que a "prescrição da «intensidade» está intimamente relacionada com a prescrição do "volume»". Tal é em parte verdade dado que, como foi mencionado, o volume está integrado na intensidade, numa relação de simbiose. No entanto, ao afirmar que utiliza quase sempre, no treino, a intensidade máxima, terá então que condicionar o volume de treino ao grau de intensidade que operacionaliza, de modo a não comprometer a recuperação da equipe e dos jogadores. Sendo assim, mais do que intimamente relacionado com a intensidade, o volume deverá estar a ela subjugado.

O tipo de orientação expressa pelos treinadores para a gestão da forma desportiva da equipe e dos jogadores (TABELA 1D) é consensual entre os inquiridos, estando de acordo com as indicações da literatura. Este conceito - patamar de rendimento adequa-se à realidade das modalidades desportivas que têm um longo período de competiçôes e um relativamente curto período preparatório (SILVA, 1998).

Os resultados encontrados denotam um contrassenso. Não parece ser compatível assentar o planejamento na dinâmica da "carga", a qual arrasta a noção de "curva de forma" (entendimento dinâmico de forma desportiva) e, perspetivar simultaneamente "patamares de rendimento". Conclui-se que apesar todos os 
treinadores perspetivarem "patamar de rendimento", nem todos promovem a sua efetiva operacionalização.

A importância atribuída às componentes da "carga" (TABELA 1E) é relativa pois, como é sabido, todas elas são importantes, estando interligadas. Não se pode traçar uma visão analítica da questão. No entanto, sustentamos que o entendimento sobre a importância remete-nos para a componente gestora e orientadora.

O ciclo de supercompensação deve ser entendido como a base para a elevação funcional da eficiência do desempenho atlético (BOMPA, 2002). Este autor esclarece que este ciclo não se verifica quando: 1) o período entre dois estímulos é muito longo ("stress" insuficiente); ou 2) se trabalha cumulativamente em fadiga, por não se perspectivar com atenção necessária a recuperação ("stress" intolerável). Está bem estabelecido que a relação entre as componentes da "carga" direciona-se para a gestão do esforço e potenciação da recuperação das equipes e dos jogadores.

Reportando-se ao caso da periodização da força, BROWN e GREENWOOD (2005) salientam que a periodização diz respeito ao desenvolvimento de protocolos que otimizem o pico da performance, incluindo as estratégias de recuperação adequadas. Estes autores enfatizam a necessidade de monitorização e ajuste do esquema de periodização, de modo a eliminar as possibilidades de sobretreino e lesão. Adaptando este entendimento ao Futebol, podemos afirmar que a periodização diz respeito ao desenvolvimento de protocolos que otimizem a performance, incluindo as estratégias de recuperação adequadas, de modo a eliminar as possibilidades de lesão e sobretreino ${ }^{10}$. Destaca-se pois que a recuperação é inerente ao processo de periodização, realçando-se o impacto do "stress" físico e mental induzido pelo jogo.

Embora não a minimizem, torna-se estranho que haja treinadores que não atribuam importância máxima à problemática da recuperação (TABELA 1E). Este fato é mais relevante, sobretudo se levarmos em consideração, a intenção de trabalho em intensidade máxima, o extenso período de competiçōes, bem como, a densidade competitiva. Como nos sugere Mourinho (2002), cada vez mais os aspectos de recuperação são tão ou mais importantes que o treino propriamente dito. Há que relacionar o controle da carga com a recuperação funcional dos atletas após esforços de diferentes magnitudes e sistemas de energia (Borin, Gomes \& LeITe, 2007).

As componentes do rendimento utilizadas pelos treinadores no processo de planejamento (TABELA 2A) coincidem com as indicaçôes da literatura: a técnica, a física, a tática e a psicológica (CASTELO,
2002; Garganta, 1997, 1998, 2002; GARganta, Maia \& Marquez, 1996; Queiroz, 1986). Na ótica de evolução dos processos de prescrição do treino, Borin, Prestes e Moura (2007) aludem à necessidade de incluir todos os fatores, detalhando a intervenção ao nível de cada uma das componentes mencionadas e suas relações.

O treinador deve evidenciar a "competência do tempo" permitindo uso e gestão eficiente (MEINBERG, 2002). Para se maximizar o tempo de treino, as dimensões supracitadas devem ser operacionalizadas em comunhão, de forma articulada, sob orientação do modelo de jogo e da dimensão tática. Este entendimento parece ser a visão adotada pela maioria dos treinadores (TABELA 2B, 2C, 2D e 4B). Os resultados parecem não ratificar as conclusões $\mathrm{da}$ mencionada investigação de GOMEs (2004) indiciando a não existência de congruência entre a estrutura de planificação/periodização e a implementação do modelo de jogo. $\mathrm{O}$ conhecimento das variáveis que caracterizam o modelo de jogo pode auxiliar especificamente na prescrição e controle da carga de treino, bem como na adequação dos meios e métodos de treino (Borin, Prestes \& Moura, 2007).

Alguns treinadores deverão ponderar a forma como abordam as "dimensões" que consideram determinantes para o desempenho. Não se deve perspectivar nenhum fator de treino isoladamente (CASTELO, 2002) pois o jogo é mais do que o evidente conjunto dos diversos fatores que o fundamenta (CASTELO, 1994). As componentes do rendimento devem aparecer interligadas (TeOdorescu, 2003) e integradas (CASTELO, 2006), promovendo uma operacionalidade multifatorial (CASTELO, 2002). A visão analítica é neste ponto de vista entendida como uma visão reducionista do treino. A separação artificial dos fatores que concorrem para o rendimento revela-se inoperante (Garganta, 2001a). Considerando que representam um sistema complexo (BAUER \& UEBERLE, 1988; CASTElo, 1994, 2002; GARGANTA, 1998; MARQUES, 1990), onde as relaçôes que se estabelecem entre determinam uma complexidade particular (QUEIROZ, 1986), devese atender aos efeitos interativos. A perspectiva dos sistemas desenvolveu-se como reação à abordagem reducionista que dominou a ciência durante séculos (Gréhaigne, Bouthier \& DAVID, 1997).

Os resultados obtidos na TABELA $2 \mathrm{~B}$ não estão em linha com as conclusões de um estudo de Silva, Siqueira, Crescente, Paixão Andrade e Carravetta (2004) que revela que no Futebol profissional brasileiro, o planejamento ocorre de forma predominantemente segmentada nas áreas 
física e técnico-tática. Em Portugal, parece haver uma tendência para considerar que a forma de abordagem das componentes do rendimento deve assumir uma preocupação dinâmica e dialética na sua articulação, sem excluir nenhuma delas.

Para o efeito, a investigação empírica demonstrara que no desenvolvimento da performance física, tanto os jogos reduzidos (treino específico) como a corrida intervalada sem bola (treino genérico) são igualmente efetivos enquanto modos de treino aeróbio ${ }^{11}$ intervalado $^{12}$ (Delal, Chamari, Pintus, Girard, Contte \& Keller, 2008; Hoff, Wisløff, Engen, Kemi \& Helgerud, 2002; Impellizzeri, Marcona, Castagna, Reilly, Sassi, Iaia \& Rampinini, 2006; Sassi, Reilly \& IMPELLIZZERI, 2005), apresentando-se os jogos reduzidos como substitutos aceitáveis do treino intervalado formal na manutenção da performance física durante a época competitiva (Reilly \& White, 2005). Porém, salienta-se a dificuldade de controlar a atividade dos jogadores nos diversos jogos reduzidos, surgindo uma superior variabilidade intersujeito nestes exercícios (Delal et al., 2008). Esta situação pode ser contornada considerando que a monitorização da frequência cardíaca durante o exercício específico de futebol destaca-se como um indicador válido da intensidade atual desse exercício (Hoff et al., 2002). Permite determinar a carga cardiovascular real de cada jogador no sentido de otimizar a sessão de treino, ou controlar o cumprimento dos estímulos fisiológicos determinados durante o planejamento do treino (RAMPININI, SASSI \& IMPELLIZZERI, 2005). Por seu turno, surge a necessidade em considerar que as exigências da performance são diferentes entre as posições dos jogadores em campo, tornando-se importante introduzir sessóes de treino específico que levem em consideração essas diferenças (Di Salvo, Baron \& Cardinale, 2007).

O impacto fisiológico dos distintos jogos reduzidos (ex. $2 \times 2,3 \times 3,4 \times 4)$ depende das características desses exercícios (número de jogadores, tempo de exercitação/recuperação, área de jogo, etc.), sendo possível modificar cada exercício conduzindo a alteraçôes fisiológicas permitindo manter os mesmos aspetos técnicos e táticos (Aroso, Rebelo \& Gomes-Pereira, 2004).

Pelo exposto, surge a possibilidade regular o exercício de treino específico, particularmente pela utilização dos diversos jogos reduzidos, implicando aspectos físicos, técnicos e táticos. Outro tipo de exercícios específicos podem também ser utilizados cumprindo os objetivos do treino físico e outros. Hoff et al. (2002) demonstram a utilização de um exercício de drible como treino aeróbio intervalado. Por sua vez, SASSI, Reilly e Impellizzeri (2005) avaliaram a utilização de exercícios para o treino técnico-tático evidenciando-os como um desafio moderado ao sistema circulatório, apresentandoos como mais compatíveis com programas de manutenção ou recuperação nos dias seguintes aos jogos. Apontam-se pois diversas possibilidades como opçōes metodológicas a utilizar no treino.

A "dimensão" tática deverá ser a matriz configuradora do planejamento, implicando as restantes “dimensões" (ver Silva, Santos \& Marques Júnior, 2009). No Futebol, os fatores de execução técnica são sempre determinados por um contexto tático (Garganta \& Pinto, 1998). O mesmo se verifica nos aspectos físicos ditados pela utilização das diferentes formas de locomoção no jogo (GARGANTA, 2001b). É na tática e, através dela, que se consubstanciam os comportamentos que ocorrem ao longo duma partida (GARGanta, 1997, 2001b). CASTElo (1999) retifica esta noção. Podemos associar a tática a um conceito mais genérico alusivo à cultura de jogo. Deste ponto de vista, aludimos à componente tático-técnica, colaborando das ideias da generalidade dos treinadores (TABELA 2C e 2D).

Não querendo negar a importância decisiva do treino da vertente física, SoAres (2005) deixa claro que o jogo de Futebol é muito mais do que a expressão das capacidades físicas. BANGSBO (1993) concorda, realçando que um nível físico excecional por si só não é crucial ao jogador de alto nível dado que o desempenho também é influenciado pelas capacidades técnicas, táticas e psicológicas. Pela investigação empírica, Di SAlvo, Gregson, TorDOFF e Drust (2009) indiciam que a eficácia geral técnica e tática da equipe em vez de elevados níveis de performance física per se, são mais importantes para determinar o sucesso no Futebol.

O treino das capacidades físicas, desprovido da sua relação com o verdadeiro significado do Futebol, esquece, frequentemente, a relação que deveria existir com o modelo de jogo, não maximizando a sua utilidade para a forma de jogar que se pretende cultivar na equipe (Silva, Santos \& Marques Junior, 2009). Conforme a indicação de Oliveira (1991), a "dimensão" física não deverá ser a orientadora do processo, apesar de assumir um papel igualmente importante, surgindo em paralelo, mas de forma condicionada pela componente guia do processo - a tática.

Parece ser incontornável afirmar que o Futebol irrompe como um imperativo tático. Este particularidade pressupõe uma abrangência e articulação com as demais dimensões. A “dimensão" tática assume-se como uma transdimensão, ou como refere OlIVEIRA 
(2004b), uma dimensão unificadora que a projeta para lá do conceito das "dimensões" tradicionais do jogo. Nem todos os treinadores reconhecem a centralidade e visão unificadora da dimensão tática e que o planejamento da componente considerada central desencadeia o "arrastamento" das outras (TABELA 2C e 2D).

Encarando o entendimento expresso, ao considerar o principal tipo de planejamento utilizado (TABELA 2D e 2E), alguns clubes devem refletir com mais acuidade sobre a real importância da dimensão física no seio do planejamento. Não se pretende minorar a relevância de aspectos físicos mas salientar a forma de jogar da equipe, e neste sentido, os aspectos táticos e de organização de jogo. Apontemos que segundo GARGANTA (2008) o processo de treino consiste na implementação de uma "cultura para jogar", que se traduz num estado dinâmico de prontidão, com referência a conceitos e a princípios.

Verifica-se coerência entre o entendimento do aspecto percepcionado como central ao nível do planejamento do treino em Futebol (TABELA 2C), e o principal tipo de planejamento utilizado pelos treinadores inquiridos para preparar a equipe para o jogo (TABELA 2D). Ao relacionar com os dados da TABELA 1D e 1A, conclui-se que, embora a maioria dos treinadores refiram operacionalizar um planejamento com base na componente "tática", apenas uma minoria o faz sem atender às fases da forma desportiva, assentes na dinâmica da "carga" e sem considerar a divisão da época em períodos, com diferenças de manipulação no volume e na intensidade.

No que concerne a hierarquia entre as componentes do rendimento (TABELA 3), a literatura parece indiciar uma importância tendencialmente similar. Nem todos os treinadores inquiridos suportam este ponto de vista.

Num estudo realizado por Garganta, MaIA e MARQUES (1996), também apresentado por GARGANTA (1997), concluiu-se que embora exista uma ligeira hierarquização dos fatores do rendimento ${ }^{13}$, esta não é muito expressiva, existindo equilíbrio no valor das cotações atribuídas. Embora a dimensão tática deve emergir como fundadora do processo (CASTELO, 1999; GARGANTA, 1997, 1999, 2002; GARGANTA, MaIA \& MarQUES, 1996; Oliveira, 1991, 2004a, 2004b), as diferentes dimensões assumem uma importância similar na sua construção, desenvolvimento e manifestação (OlIVEIRA, 2004a). Apesar de se assumir como núcleo diretor do jogo de Futebol (GARGANTA, 1997; GARGANTA, MAIA \& MARQUES, 1996), a dimensão tática não é mais relevante que as demais dimensões. Tal ponto de vista entronca na opiniāo da generalidade dos treinadores.
Ainda há treinadores que relativizam a interesse do modelo de jogo (TABELA 4). Contudo, constata-se que a modelação do jogo é uma tendência evolutiva dos processos de treino e de jogo no principal escalão competitivo do Futebol português. No Futebol, o centro do processo de treino deve ser o jogo, mais concretamente o jogo que pretendemos, o que nos referencia a um modelo de jogo. Convocamos GARGANTA (2008) para salientar que a forma de jogar é construída consistindo o treino em modelar os comportamentos e atitudes dos jogadores/equipes, através de um projeto orientado para o conceito de jogo/competição. Parece consensual na literatura a ideia da necessidade de se proceder à definição e caracterização de um modelo de jogo (ver CASTElo, 1994, 1996, 2002, 2004; Carvalhal, 2001; Garganta, 1997, 2000, 2003, 2004; GARGANTA \& Pinto, 1998; Gomes, 2004; Oliveira, 1991, 2003, 2004a, 2004b; QueIroz, 1986; QuintA, 2004), i.e., de um conceito de jogo a atingir, que tem por referência uma cultura de jogo. Os dados (TABELA 4) colocam o modelo de jogo nos centro do processo de treino e de jogo na generalidade dos clubes inquiridos. Confirmam a convicção manifesta por BОмРА (2002) que, apesar de não ser uma descoberta recente, a modelação irá progressivamente tornar-se um dos mais importantes princípios do treino.

Os treinadores que empregam um modelo de jogo como elemento orientador do processo de treino e de jogo parecem usar procedimentos adequados na sua elaboração. Todos definem comportamentos alusivos ao plano de jogo coletivo e individual (TABELA 5A) e, embora nem todos o façam, a maioria procura estruturar um documento escrito (TABELA 5B). Por outro lado, os momentos que o modelo apresenta em cada caso (TABELA 5C) são, para a generalidade, coincidentes com as referências que encontramos na literatura. Quando equacionados, permitem enquadrar as exigências e especificidade da organização do jogo de Futebol. A questão prende-se com a qualidade do conteúdo.

A sistematização mental das ideias de jogo (TABELA 5B) é um critério insuficiente para explorar as potencialidades da elaboração e utilização de um modelo de jogo como elemento guia dos processos de treino e de jogo. Estruturar um documento escrito permite uma sistematização clara de ideias e garante uma reflexão mais objetiva e coerente, tornando possíveis discussões exatas. Tal documento irá expressar as descontinuidades e roturas inerentes ao processo de construção do modelo, espelhando as suas coerências e evoluçôes. O modelo de jogo deverá estar aberto a 
novos acrescentos (CASTELO, 1994, 1996; OliveIRA, 2003), pelo que estando em contínua construção, nunca sendo um dado adquirido (OliveIrA, 2003). Justifica-se este esforço de elaboração dum documento, clarificando conceitos e a linguagem utilizada.

Nenhum treinador divulgou o modelo da principal equipe do clube aos escalóes de formação (TABELA 5B). Seria importante investigar as causas subjacentes a esta atitude.

Embora se possa circunscrever a três os momentos fundamentais do jogo de Futebol: 1) a posse de bola (ataque); 2) a posse da bola por parte do adversário (defesa) e; 3) as alterações na posse de bola (transição) (Romero Cerezo, 2000), é usual considerar a existência de quatro momentos (Oliveira, 2004a): organização ofensiva, organização defensiva, transição defesa/ataque e transição ataque/defesa. É possível ter uma visão mais pormenorizada da organização do jogo, perspetivando ainda como momento os fragmentos constantes do jogo (vulgo lances de bola) (SousA, 2005). Este conceito não é novo na medida em que WRZOS (1981) se reporta aos "modos de execução dos fragmentos constantes de jogo". Importa ainda realçar que os momentos do jogo evidenciam relações muito estreitas entre si, sendo a separação apenas didático-metodológica (OliveIra, 2003).

Apesar da maioria dos treinadores inquiridos utilizar os cinco momentos que a literatura indica (ver TABELA 5C), apresentam outras opçóes.
Estas, não podem ser consideradas momentos. Tais respostas evidenciam que os referidos treinadores não dominam corretamente o conceito de momentos do jogo. Um momento do jogo ${ }^{14}$ refere-se a uma sequência de açôes do jogo da equipe, com uma lógica e identidade comum, e que tem por referência a organização do jogo de ambas as equipes.

Embora não seja a ideia defendida pela maioria dos treinadores, há quem entenda que devem ser os jogadores a ajustarem-se ao modelo de jogo inicialmente delineado pelo treinador (TABELA 5D). É preciso ao referir que o modelo de jogo deriva (CASTELO, 2006): 1) das concepçôes de jogo do treinador; 2) das adaptações relativamente às reais capacidades dos jogadores e; 3 ) das possibilidades de evolução num futuro próximo (margens de progressão dos jogadores). Na definição de um modelo de jogo é importante conhecer: 1) o clube em questão; 2) a equipe e o respectivo nível de jogo; 3) o nível e as características individuais dos jogadores; 4) o calendário competitivo; e 5) os objetivos a atingir (Mourinho, 2001).

O modelo de jogo deverá ser um instrumento útil ao serviço das equipes e dos jogadores, funcionando como atrator da forma de jogar de uma equipe e uma referência de coerência para o processo de planejamento do treino. A sua lógica estabelecerá pontes sinérgicas entre o treino e o jogo, enquadrando a noção de especificidade na preparação das equipes para o sucesso competitivo.

\section{Conclusões}

Embora pareça não ser a corrente de treino dominante, o paradigma da dimensão física do treino aparece ainda bastante vincado no principal escalão de futebol português. Alguns dos pressupostos associados à concepção tradicional do treino permanecem presentes no trabalho realizado na Superliga, sendo frequentemente utilizados.

Neste nível competitivo, parece ser costume operacionalizar um planejamento com base na dimensão tática. Apesar desta ser a "guia" do processo, e "arrastar" a dimensão física, nem sempre tal se verifica.

Embora surjam situaçōes em que ainda se promove a separação das dimensões do rendimento, a referência passa por trabalhá-las, sempre que possível, simultaneamente.

Embora não seja reconhecido e empregue por todos os clubes, o modelo de jogo é uma referência relevante para a orientação e organização do processo de treino e jogo na generalidade dos clubes investigados. Nestes, é utilizado como agente condicionador de uma determinada forma de se jogar. A modelação é uma tendência empregue.

Alguns treinadores revelaram uma confusão relativa à definição do conceito de momentos do jogo.

Foram identificados casos pontuais de contradições entre a forma de pensar (concepção acerca do planejamento) e de agir (execução do treino) dos treinadores inquiridos. Nem todos agem de acordo com as suas convicçôes expressas.

Considerando que todos os fatores que melhoram a qualidade do treino devem ser utilizados de modo eficaz, sendo constantemente melhorados (BOMPA, 2002), teremos de apresentar um elevado espírito crítico de reflexão para que as decisões operadas ao nível dos processos de planejamento não sejam contraditórias com as intenções manifestas. 


\section{Abstract}

The training planning and periodization processes in professional football Portuguese league 2004/2005

Planning and periodization are assumed to be crucial phases directly implied in the efficiency, consistency and game quality of the teams. The aim of this work is to investigate: 1) the implementation of the "load's" dynamics and its relation to periods; 2 ) "load' s" components and recovery importance; 3 ) intensity prescription; 4) the performance components considered in planning, its importance, hierarchy, and how they are developed; 5) the main aspect in planning; 6) the type of planning used in the team preparation; 7) the importance of game model in the training process. The universe under study is constituted by the eighteen "Superliga" teams in the $2004 / 2005$ season. It was applied an inquiry by questionnaire validated by seven specialists. In representation of each one of the studying teams, this questionnaire was answered by sixteen main coaches and two assistant-coaches, by indication of the main coach. Although the results suggest that the paradigm of the physical dimension seems not to be the dominant training current, it still appears rather emphasized in "Superliga". Some of the assumptions associated to the traditional training conception remain present in the work carried through, and are being frequently used. It seems to be usual to operate a planning based on the tactical dimension. In fact, this dimension is considered to be the "guide" of the process, and "drags" the physical dimension. Nevertheless, this doesn't always happen. There are situations where the separation of the training factors is established; however the reference passes for working them, as always as possible, simultaneously. There is consensus in matter of the valuation given to the game model. Not all the coaches act according to their expressed beliefs.

UnITERMS: Soccer; Training; Planning; Periodization.

\section{Notas}

1. O paradigma da dimensão física realça que a construção de uma base de forma desportiva deve centrar-se na dinâmica da "carga", definindo a "dimensão" física como o aspecto central do planejamento e da periodização.

2. Council for International Organizations of Medical Siences e Organização Mundial da Saúde

3. Segundo os inquiridos, os outros momentos contemplados no modelo de jogo são respetivamente, em cada caso: 1) a interiorização do objetivo; 2) a capacidade de estar preparado para enfrentar contratempos; 3) a capacidade de controle emocional do jogo; 4) a estratégia adotada; 5) todas as estratégias que permitam à equipe, quando em processo ofensivo, criar desnorte ao adversário; 6) o encurtamento interzonal.

4. Destacam-se $38 \%$ de treinadores que acrescentam outros momentos contemplados no seu modelo de jogo, designadamente, em cada caso: 1) a interiorização do objetivo; 2) a capacidade de estar preparado para enfrentar contratempos; 3) a capacidade de controle emocional do jogo; 4) a estratégia adotada; 5) todas as estratégias que permitam à equipe, quando em processo ofensivo, criar desnorte ao adversário; 6) o encurtamento interzonal.

5. Divisões: "Superliga" $\mathrm{n}=12$, "II Liga" $\mathrm{n}=8$, "II B" $\mathrm{n}=10$, "Seleção nacional" $\mathrm{n}=2$ e, "sem clube" $\mathrm{n}=3$.

6. Sinteticamente os três níveis de forma propostos por Bompa (1984, citado por GARGANTA, 1993) são: 1) o nível de forma desportiva geral: elevado desenvolvimento das capacidades condicionais requeridas para a prática desportiva; 2) o nivel de alta forma desportiva: estado biológico superior, traduzido por uma rápida adaptabilidade às cargas de treino, eficaz ritmo de recuperação e bons níveis de execução técnica e tática, apoiados nas capacidades psíquicas necessárias ao desenvolvimento desportivo; 3) o nível de forma ótima: estado de rendimento máximo em que os níveis de execução técnica e resolução tática são ótimos. Devido às suas características, o "estado de forma ótima” é mais elevado mas menos durável do que qualquer dos outros.

7. Esta obra é um marco de referência de determinada visão do treino em futebol.

8. O ciclo da supercompensação é o principal conceito da teoria do treino desportivo, cujo dinâmica depende do planejamento da intensidade do treino, assegurando a restauração da energia, auxiliando a evitar níveis críticos de fadiga (BOMPA, 2002).

9. Dada a ambiguidade de que se reveste a noção de intensidade máxima, ao nível do Futebol, OLIVEIRA (2006) apresenta o conceito de intensidade máxima relativa: trata-se da intensidade necessária para se realizar com êxito um determinado exercício de jogo, 
i.e., a execução que permite ao jogador ter êxito na situação em que se encontra (parte qualitativa do jogo). Neste sentido, este conceito incorpora aspectos qualitativos do jogo, relacionando-se com a execução que visa o êxito face ao contexto.

10. O sobretreino resulta de um desequilíbrio entre o treino e a recuperação (ver Rebelo, 2001).

11. Helgerud, Engen, Wisløff e Hoff (2001) demonstraram que a melhoria da resistência aeróbia em jogadores de futebol aprimorou a performance pelo aumento da distância percorrida, intensidade de trabalho, número de "sprints" e envolvimentos com a bola durante uma partida.

12. Segundo Rodas, Ventura, Cadefau, Cussó e Parra (2000), está documentado que o metabolismo aeróbio pode ser desenvolvido pelo exercício contínuo de resistência ou através de porçōes repetidas de exercício intenso. Porém, citando outros autores, esclarecem que o exercício contínuo não desenvolve o metabolismo anaeróbico, enquanto que a utilização de porções de exercício intenso pode fazê-lo.

13. O estudo reporta-se à hierarquização dos fatores que tradicionalmente se aceita contribuírem para o rendimento no Futebol: físicos, psicológicos, táticos e técnicos.

14. Partindo da definição apresentada no Dicionário da Língua Portuguesa Contemporânea da Academia de Ciências de Lisboa, podemos associar à noção de momento, um espaço de tempo indeterminado, breve, que será determinado por referência a um acontecimento, coincidente com a realização de uma determinada ação. Transpondo esta ideia para o caso do Futebol obtemos a definição apresentada.

\section{Referências}

ABRANTES, J. Anatoly Bondartchuk em Lisboa com revolucionária programação de treino. Atletismo, Lisboa, n.122, p.25-9, 1992. ALVAREZ DEL VILLAR, C. La preparacion física del futbol basada en el atletismo. 3. ed. Madrid: Gymnos Editorial, 1987. AROSO, J.; REBELO, N.; GOMES-PEREIRA, J. Physiological impact of selected game-related exercises. Journal of Sports Sciences, London, v.22, n.6, p.522, 2004.

ARRUDA, M.; GOULART, L.; OLIVEIRA, P.; PUGGINA, E.; TOLEDO, N. Futebol: uma nova abordagem de preparação física e sua influência na dinâmica da alteração dos índices de força rápida e resistência de força em um macrociclo. Revista Treinamento Desportivo, Lisboa, v.4, n.1, p.23-8, 1999.

BANGSBO, J. The physiology of soccer: with special reference to intense intermittent exercise. Copenhagen: HO+Storm, 1993. BANGSBO, J.; MOHR, M.; KRUSTRUP, P. Physical and metabolic demands of training and match-play in the elite football player. Journal of Sports Sciences, London, v.24, n.7, p.665-74, 2006.

BAUER, G.; UEBERLE, H. Fútbol: factores de rendimiento, dirección de jugadores y del equipo. Barcelona: Martínez Roca, 1988. BOMPA, T. Periodização: teoria e metodologia do treinamento. São Paulo: Phorte, 2002.

BORIN, J.; GOMES, A.; LEITE, G. Preparação desportiva: aspectos do controle da carga de treinamento nos jogos colectivos. Revista da Educação Física, Maringá, v.18, n.1, p.97-105, 2007.

BORIN, J.; PRESTES, J.; MOURA, N. Caracterização, controle e avaliação: limitações e possibilidades no âmbito do treinamento desportivo. Revista Treinamento Desportivo, Lisboa, v. 8, n.1, p.6-11, 2007.

BRAZ, J. Organização do jogo e do treino em futsal: estudo comparativo acerca das concepçôes de treinadores de equipas de rendimento superior de Portugal, Espanha e Brasil. 2006. Dissertação (Mestrado em Ciências do Desporto) - Faculdade de Ciências do Desporto e Educação Física, Universidade do Porto, Porto, 2006.

BROWN, L.; GREENWOOD, M. Periodization essentials and innovations in resistance training protocols. Strength and Conditioning Journal, Champaign, v.27, n.4, p.80-5, 2005.

CARVALHAL, C. No treino de futebol de rendimento superior: a recuperaçãoé... .muitíssimo mais que "recuperar". Braga: Liminho, 2001. CASTELO, J. A lógica interna do jogo de futebol. Ludens, Lisboa, v.1, n.16, p.21-32, 1999.

. Futebol: a organização do jogo. Lisboa: Edição do autor, 1996.

Futebol: conceptualização e organização prática de 1100 exercícios específicos de treino. Lisboa: Visão e Contextos, 2006. Futebol: modelo técnico-táctico do jogo. Lisboa: FMH, 1994.

O exercício de treino: o acto médico versus o acto do treinador. Ludens, Lisboa, v.1 n.17, p.35-54, 2002.

Os métodos de treino do Futebol. Ludens, Lisboa, v.4, n.17, p.41-74, 2004.

DELlAL, A.; CHAMARI, K.; PINTUS, A.; GIRARD, O.; CONTTE, T.; KELLER, D. Heart rate responses during small.sided games and short intermittent running training in elite soccer players: a comparative study. Journal of Strength and Conditioning Research, Champaign, v.22, n.5, p.1449-57, 2008. 
DI SALVO, V.; BARON, R.; CARDINALE, M. Time motion analysis of elite footballers in European cup competitions. Journal of Sports Science and Medicine, Bursa, v.6, p.14-5, 2007. Supplement 10.

DI SALVO, V.; GREGSON, W.; ATKINSON, G.; DRUST, B. Analysis of high intensity activity in premier league soccer. International Journal of Sports Medicine, Stuttgart, v.30, n.3, p.205-12, 2009.

GARGANTA, J. Atrás do palco, nas oficinas do futebol. In: GARGANTA, J.; OLIVEIRA, J.; MURADA, M. (Eds.). Futebol: de muitas cores e sabores. Reflexões em torno do desporto mais popular do mundo. Porto: FCDEF-UP, 2004. p.228-34.

. Fútbol: del juego al entrenamiento, del entrenamiento al juego. Training Fútbol, Valladolid, n. 85, p.14-7, 2003. Futebol e ciência: ciência e futebol. Lecturas: Educación Física y Deportes, Buenos Aires, v.7, n.40, 2001 a.

Disponível em: <http://www.efdeportes.com/efd40/fcienc.htm>. Acesso em: 12 fev. 2004.

. La prestacion energetico funzionale del calciatore. Teknosport, Candia di Ancona, n.11, p.18-27, 1999.

. Modelação táctica do jogo de futebol. 1997. Dissertação (Doutoramento em Ciências do Desporto) - Faculdade de Ciências do Desporto e Educação Física, Universidade do Porto, Porto, 1997.

Modelação táctica em jogos desportivos: a desejável cumplicidade entre pesquisa, treino e competição. In:

TAVARES, F.; GRAÇA, A.; GARGANTA, J.; MESQUITA, I. (Eds.). Olhares e contextos da performance nos jogos desportivos. Universidade do Porto: Faculdade de Desporto, 2008. p.108-21.

O treino da táctica e da estratégia nos jogos desportivos. In: GARGANTA, J. (Ed.). Horizontes e órbitas no

treino dos jogos desportivos. Porto: FCDEF-UP, 2000. p.51-61.

O treino da táctica e da técnica nos jogos desportivos à luz do compromisso cognição-acção. In: BARBANTI,

V.; BENTO, J.O.; MARQUES, A.T., AMADIO, A.C. (Eds.). Esporte e atividade física: interação entre rendimento e saúde. São Paulo: Manole, 2002. p.281-306.

Para uma teoria dos jogos desportivos colectivos. In: GRAÇA, A.; OLIVEIRA, J. (Eds.). O ensino dos jogos

deportivos. 3. ed. Porto: Centro de Estudos dos Jogos Desportivos/FCDEF-UP, 1998. p.11-26.

Planeamento e periodização do treino em Futebol. Horizonte, Lisboa, v.VII, n.42, p.196-200, 1991.

Programação e periodização do treino em futebol: das generalidades à especificidade. In: BENTO, J.O.; MAR-

QUES, A. (Eds.). A ciência do desporto, a cultura e o homem. Porto: FCDEF-UP, 1993. p.259-70.

Tactical modelling: a critical view. In: HUGUES, M.; TAVARES, F. (Eds.). Prooceedings of IVWorld Congress

of Notational Analysis of Sport. Porto: FCDEF, 2001b. p.33-40.

GARGANTA, J.; MAIA, J.; MARQUES, A. Acerca da investigação dos factores de rendimento em futebol. Revista Pau-

lista de Educação Física, São Paulo, v.10, n.2, p.146-58, 1996.

GARGANTA, J.; PINTO, J. O ensino do futebol. In: GRAÇA, A.; OLIVEIRA, J. (Eds.). O ensino dos jogos deportivos.

3. ed. Porto: Centro de Estudos dos Jogos Desportivos/FCDEF-UP, 1998. p.95-135.

GODOY, E.; OLIVEIRA, A.; ARAUJO, C.; SEQUEIROS, J.; BARBOSA, L.; COSTA, L.; PORTAL, M.; SILVA, M.; AZEVEDO, R.; DANTAS, E. Verificação da consistência das críticas à periodização clássica. Revista Portuguesa de Ciências do Desporto, Porto, v.4, n.2, p.214, 2004. Suplemento.

GOMES, J. Estudo da congruência entre a periodizaçáo do treino e os modelos de jogo, em treinadores de futebol de alto rendimento. 2004. Dissertação (Mestrado em Ciências do Desporto) -F aculdade de Ciências do Desporto e Educação Física, Universidade do Porto, Porto, 2004.

GRÉHAIGNE, J.; BOUTHIER, D.; DAVID, D. Dynamic-system analysis of opponent relationships in collective actions in soccer. Journal of Sports Sciences, London, v.15, n.2, p.137-49, 1997.

HELGERUD, J.; ENGEN, L.; WISLØFF, U.; HOFF, J. Aerobic endurance training improves performance. Medicine \& Science in Sports \& Exercise, Madison, v.33, n.11, p.1925-31, 2001.

HOFF, J.; WISLØFF, U.; ENGEN, L.; KEMI, O.; HELGERUD, J. Soccer specific aerobic endurance training. British Journal of Sports Medicine, London, v.36, n.3, p.218-21, 2002.

IMPELLIZZERI, F.; MARCORA, S.; CASTAGNA, C.; REILLY, T.; SASSI, A.; IAIA, F.; RAMPININI, E. Physiological and performance effects of generic versus specific aerobic training in soccer players. International Journal of Sports Medicine, Stuttgart, v.27, n.6, p.483-92, 2006.

MARQUES, A. Treino desportivo: área de formação e investigação. Horizonte, Lisboa, v.VII, n.39, p.97-106, 1990. MEINBERG, E. Training: a special form of teaching. Revista Portuguesa de Ciências do Desporto, Porto, v.2, n.42, p.115-23, 2002.

MOURINHO, J. Das teorias generalistas... à ESPECIFICIDADE do treino em futebol. Leiria: Escola Superior de Educação de Leiria/Instituto Politécnico de Leiria, 2001. Disponível em: <http://docentes.esel.ipleiria.pt/joaocruz/POAEF. htm>. Acesso em: 24 Out., 2004. (Palestra realizada na ESEL, Disciplina POAEF). 
. Entrevista a José Mourinho. Dragóes, Porto, 2001, p.15-35, 2002.

OLIVEIRA, J. Conhecimento específico em futebol: contributos para a definição de uma matriz dinâmica do processo ensino-aprendizagem/treino do Jogo. 2004. Dissertação (Mestrado em Ciências do Desporto) - Faculdade de Ciências do Desporto e Educação Física, Universidade do Porto, Porto, 2004 a.

. Ente o sonho e a realidade, um mundo de expectativas e compromissos. In: GARGANTA, J.; OLIVEIRA, J.; MURADA, M. (Eds.). Futebol: de muitas cores e sabores. Reflexões em torno do desporto mais popular do mundo Porto: FCDEF/UP, 2004b. p.235-8.

. Entrevista. In: GOMES, M. Do pé como técnica ao pensamento técnico dos pés dentro da caixa preta da periodizaçáo táctica: um estudo de caso. 2006. Dissertação (Licenciatura em Desporto e Educação Física) - Faculdade de Ciências do Desporto e Educação Física, Universidade do Porto, Porto, 2006.

"Especificidade, o "pós-futebol” do "pré-futebol”: um factor condicionante do alto rendimento desportivo. 1991. Monografia (Licenciatura em Desporto e Educação Física) - Faculdade de Ciências do Desporto e Educação Física, Universidade do Porto, Porto, 1991.

Organização do jogo de uma equipa de futebol: aspectos metodológicos na abordagem da sua organização estrutural e funcional. In: JORNADAS TÉCNICAS DE FUTEBOL + FUTSAL DA UTAD, 2., Vila Real, 2003. Anais... Vila Real: UTAD, 2003.

PANTALEÃO, D.; ALVERANGA, R. Análise de modelos de periodização para o futebol. Lecturas: Educación Física y Deportes, Revista digital, Buenos Aires, v.13, n.119, 2008. Disponível em: <http://www.efdeportes.com/efd119/analisede-modelos-de-periodizacao-para-o-futebol.htm>. Acesso em: 2 maio 2009.

PINTO, J. A caracterização do esforço no futebol e algumas das suas implicações no treino. In: BENTO, J.; MARQUES, A. (Eds.). Actas do II Congresso de Educação Física dos Países de Língua Portuguesa: as ciências do desporto e a prática do desporto Porto: FCDEF/UP, 1991. p.23-34.

QUEIROZ, C. Estrutura e organização dos exercícios de treino em futebol. Lisboa: Federação Portuguesa de Futebol, 1986. QUINTA, R. Modelo de jogo: da teoria à prática. In: JORNADAS TÉCNICAS DE FUTEBOL + FUTSAL, 3., Vila Real, 2004. Anais... Vila Real: UTAD, 2004.

RAMPININI, E.; SASSI, A.; IMPELLIZZERI, F. Reliability of heart rate recorded during soccer training. In: REILLY, J.T.; CABRI, J.; ARAÚJO, D. (Eds.). Science and football V. Oxon: Routledge, 2005. p.359-64.

REBELO, A. O sobretreino em futebol. Porto: FCDEF-UP, 2001.

REILLY, T.; WHITE, C. Small-sided games as an alternative to interval training for soccer players. In: REILLY, J.T; CABRI, J.; ARAÚJO, D. (Eds.). Science and football V. Oxon: Routledge, 2005. p.355-8.

RODAS, G.; VENTURA, J.; CADEFAU, J.; CUSSÓ, R.; PARRA, J. A short training programme for the rapid improvement of both aerobic and anaerobic metabolism. European Journal of Applied Physiology, Leeds, v.82, n.6, p.480-6, 2000. ROMERO CEREZO, C. Hacia uma concepción más integral del entrenamiento en el fútbol. Lecturas: Educación Física y Deportes, Buenos Aires, v.5, n.19, 2000. Disponível em: <http://www.efdeportes.com/efd19a/futbol.htm>. Acesso em: 8 nov. 2004. SASSI, R.; REILLY, T.; IMPELLIZZERI, F. A comparison of small-side games and interval training in elite professional soccer players. In: REILLY, J.T.; CABRI, J.; ARAÚJO, D. (Eds.). Science and football V. Oxon: Routledge, 2005. p.352-4. SEQUEIROS, J.; CASTANHEDE, D.; OLIVEIRA, A.; DANTAS, E. Estudo sobre a fundamentação do modelo de periodização de Tudor Bompa do treinamento desportivo. Fitness \& Performance Journal, Rio de Janeiro, v.4, n.6, p.341-7, 2005. SILVA, E.; SIQUEIRA, O.; CRESCENTE, L.; PAIXĀO, L.; ANDRADE, A.; CARRAVETTA, B. Planejamento dos treinamentos físico, técnico e táctico no futebol profissional brasileiro. Revista Portuguesa de Ciências do Desporto, Porto, v.4, n.2, p.215, 2004. Suplemento.

SILVA, F.; MARTINS, C.; SILVA, K. Dinâmica competitiva no futebol de alta competição e a teoria da periodização do treino. Revista Portuguesa de Ciências do Desporto, Porto, v.4, n.2, p.215, 2004. Suplemento.

SILVA, M. Caracterização do esforço em modalidades desportivas mensuráveis e não mensuráveis: o judo como caso exemplar. Treino Desportivo, Lisboa, n.10, p.36-46, 1988.

. Planeamento do treino. Treino Desportivo, Lisboa, n.4, p.3-12, 1998.

SILVA, P.M; SANTOS, P.M.O.; MARQUES JUNIOR, N.K. Treinar futebol respeitando a essência do jogo: o exemplo do salto como ação táctica e não somente técnico-física. Conexões, Campinas, v.7, n.2, p.38-69, 2009.

SOARES, J. O treino do futebolista. Porto: Porto Editora, 2005.

SOUSA, P. Organização do jogo de futebol: proposta de mapeamento de situações tácticas a partir da revisão da literatura e do entendimento de peritos. 2005. Monografia (Mestrado em Ciências do Desporto) - Faculdade de Ciências do Desporto e Educação Física, Universidade do Porto, Porto, 2005. 
TANI, G. Aprendizagem motora e esporte de rendimento: um caso de divórcio sem casamento. In: BARBANTI, V.; BENTO, J.O.; MARQUES, A.T., AMADIO, A.C. (Eds.). Esporte e atividade física: interação entre rendimento e saúde. São Paulo: Manole, 2001. p.145-62.

TEODORESCU, L Problemas de teoria e metodologia nos jogos desportivos. 2. ed. Lisboa: Livros Horizonte, 2003. WILLIAMS, A.; HODGES, N. Practice, instruction and skill acquisition in soccer: challenging tradition. Journal of Sports Sciences, London, v.23, n.6, p.637-50, 2005.

WRZOS, J. Análisis del juego ofensivo de los mejores equipos de los Campeonatos Mundiales de Fútbol de 1978. El Entrenador Español, Madrid, n.10, p.12-9, 1981.

ANEXO I - Material suplementar autorizado pelo Autor.

CASTELO, J.F.F. O planeamento e a periodização do treino em futebol: um estudo realizado em clubes da superliga. 2006. Dissertação (Mestrado em Treino de Alto Rendimento) - Faculdade de Motricidade Humana, Universidade Técnica de Lisboa, Lisboa, 2006. Disponível em: <http://www.diaadiaeducacao.pr.gov.br/diaadia/diadia/arquivos/File/conteudo/ artigos_teses/EDUCACAO_FISICA/dissertacao/Pedro_Santos.pdf>.

ENDEREÇO

Pedro Santos

R. 25 de abril, 437, 1o. Esquerdo 4710-913 - Braga - PORTUGAL e-mail: pmosantos@gmail.com
Recebido para publicação: 18/01/2010

1a. Revisão: 06/ 12/ 2010

2a. Revisão: 08/07/ 2011

3a. Revisão: $18 / 07 / 2011$

Aceito: 04/08/2011 